\title{
Frequent promoter hypermethylation of tumor-related genes in head and neck squamous cell carcinoma
}

\author{
KATRIN STEINMANN ${ }^{1 *}$, ANNETT SANDNER ${ }^{2 *}$, \\ UNDRAGA SCHAGDARSURENGIN $^{1}$ and REINHARD H. DAMMANN ${ }^{1}$ \\ ${ }^{1}$ Institute for Genetics, Justus-Liebig University Giessen, Giessen; \\ ${ }^{2}$ Department of Otolaryngology, Martin-Luther University Halle-Wittenberg, Germany
}

Received June 25, 2009; Accepted September 4, 2009

DOI: 10.3892/or_00000596

\begin{abstract}
Squamous cell carcinomas of head and neck (HNSCC) are a result of multiple genetic and epigenetic alterations. Epigenetic inactivation of tumor suppressor genes is an important event in head and neck carcinogenesis. Here we analyzed the promoter methylation of 15 genes (RASSF1A, p16, MGMT, DAPK, RARß, MLH1, CDH1, GSTP1, RASSF2, RASSF4, RASSF5, MST1, MST2, LATS1, LATS2) in 54 HNSCC and in matching 23 normal tissues. Methylation of these tumor-related genes (TRG) was significantly more frequent in HNSCC (42\%) compared to normal samples $(23 \% ; \mathrm{p}<0.05)$. Particularly, methylation of $p 16$ (60\%), MGMT (53\%), DAPK (67\%), RARß (75\%), MLH1 (69\%), CDH1 (43\%), RASSF5 and MST1 (96\%) was often found in HNSCC. Methylation of RASSF1A (18\%), GSTPI (4\%), RASSF4 (13\%), MST2 (4\%), LATS1 (24\%) and LATS2 $(8 \%)$ was less frequently detected. A trend of increased TRG methylation in more advanced tumor stages and less differentiated HNSCC was observed. Methylation of $p 16$ was significantly higher in poorly differentiated HNSCC ( $\mathrm{p}=0.037$ ) and RASSF5 methylation occurred preferentially
\end{abstract}

Correspondence to: Dr Reinhard H. Dammann, Institute for Genetics, Justus Liebig University Giessen, Heinrich-Buff-Ring 58-62, D-35392 Giessen, Germany

E-mail: reinhard.dammann@gen.bio.uni-giessen.de

*Contributed equally

Abbreviations: HNSCC, head and neck squamous cell carcinomas; TRG, tumor-related genes; RASSF, ras association domain family; MGMT, O-6-methylguanine-DNA methyltransferase; DAPK1, death-associated protein kinase 1 ; RAR, retinoic acid receptor; MLH1, mutL homolog 1; CDH1, cadherin 1; GSTP1, glutathione S-transferase pi 1; MST, mammalian sterile20-like kinase; LATS, large tumor suppressor; Hpo, hippo; Sav, salvador; MSP, methylation specific PCR; COBRA, combined bisulfite restriction analysis

Key words: head and neck cancer, tumor suppressor gene, epigenetics, DNA methylation, biomarker in advanced tumor stages $(\mathrm{p}<0.05)$. Methylation of RASSF4 was higher in patients with recurrent HNSCC (23\%) than patients without relapse $(0 \% ; \mathrm{p}=0.033)$. Methylation of TRG in head and neck cancer cell lines was observed at similar frequency as in primary HNSCC. In summary, frequent hypermethylation of tumor-related genes in HNSCC was detected and this epigenetic silencing event may have an essential role in head and neck carcinogenesis.

\section{Introduction}

Squamous cell cancer of head and neck (HNSCC) is one of the most prevalent cancers in the world, with over 400,000 cases diagnosed annually (1). It accounts for $5 \%$ of all newly diagnosed cancers worldwide and is the sixth most common cancer in the world (2). Despite considerable improvements in diagnosis, treatment and understanding of the molecular mechanisms in HNSCC, the overall survival rate has remained constant at approximately $60 \%$ over the past 30 years in the United States (3). This lack of progress in prognosis is mainly due to the high loco-regional recurrence, distant metastases rate and high incidence of secondary primary tumors, which often located in the same or adjacent anatomical regions (4). Cancerous lesions are regarded as multifactorial diseases affected through multiple exogenous agents. The association between tobacco smoking and alcohol consumption and the development of HNSCC has been established (5-7).

Genetic and epigenetic alterations of tumor-related genes (TRG) caused by carcinogens contribute essentially to tumor development and tumor progression in head and neck cancer. Epigenetic silencing of TRG is mediated by aberrant methylation of $\mathrm{CpG}$ islands promoter (8). Promoter hypermethylation has been studied as a biomarker system for diagnosis and detection of early cancers and can be probably used as prognostic factor in malignant diseases (9). Hypermethylation of tumor suppressor gene is frequently found in HNSCC (10). In particular promoter methylation of $p 16$, RASSF 1A, MGMT, DAPK, CDHI and RAR $\beta$ have been described (11-18).

The aim of our study was to clarify, whether promoter hypermethylation of several tumor-related genes correlates with clinical variables, and is prognostic value in HNSCC. Therefore, we analyzed TRG involved in DNA damage avoidance and repair (GSTP1, MGMT and MLHI), in signal 
Table I. Demographic data of head and neck cancer patients.

\begin{tabular}{|c|c|}
\hline & No. $(\%)$ \\
\hline No. of patients & 54 \\
\hline Mean age (years) & $57(41-77)$ \\
\hline Male/Female ratio & $48 / 6$ \\
\hline \multicolumn{2}{|l|}{ Localization of HNSCC } \\
\hline Larynx & $20(37)$ \\
\hline Hypopharynx & $8(15)$ \\
\hline Oropharynx & $18(33)$ \\
\hline Tongue & $8(15$ \\
\hline \multicolumn{2}{|l|}{ Tumor staging } \\
\hline I & $4(7)$ \\
\hline II & 0 \\
\hline III & $12(22)$ \\
\hline IV & $38(70)$ \\
\hline \multicolumn{2}{|l|}{ T-stage } \\
\hline $\mathrm{T} 1$ & $9(17)$ \\
\hline $\mathrm{T} 2$ & $8(15)$ \\
\hline $\mathrm{T} 3$ & $23(43)$ \\
\hline $\mathrm{T} 4$ & $14(26)$ \\
\hline \multicolumn{2}{|l|}{$\mathrm{N}$-stage } \\
\hline No & $12(22)$ \\
\hline N1 & $7(13)$ \\
\hline $\mathrm{N} 2$ & $28(52)$ \\
\hline N3 & $7(13)$ \\
\hline \multicolumn{2}{|l|}{ Grading } \\
\hline Well differentiated (G1) & $7(13)$ \\
\hline Moderately differentiated (G2) & $32(59)$ \\
\hline Poorly differentiated (G3) & $15(28)$ \\
\hline
\end{tabular}

transduction $(R A S S F S)$, in differentiation $(R A R \beta)$, in cell adhesion $(C D H 1)$, in cell cycle control (p16 and LATSs), and in apoptosis (DAPK and MSTs). Methylation of TRG occurred frequently in HNSCC and hypermethylation was correlated with clinical and histopathological data.

\section{Materials and methods}

Cell lines and tissue samples. All probes were obtained from patients of the Department of Otolaryngology (University of Halle-Wittenberg) by surgical resection and were stored at $-80^{\circ} \mathrm{C}$ until use. For this study 54 squamous cell carcinomas of the head and neck and 23 corresponding macroscopically normal tissues from opposite cheek mucosa of several patients were analyzed (Table I). The average age of the investigated population was 57 years. Each tumor was scored based on the current TNM classification (19). The local medical ethics committee approved the study and all patients gave their consent. Three head and neck cell lines Hep-2 (larynx carcinoma), RPMI-2650 (nasal septum SCC) and UM-SCC-
14C (SCC) were obtained from Cell Lines Service (Eppelheim, Germany) and cultured in the recommended growth medium. DNA of patient samples and cell lines were isolated by a standard phenol/chloroform extraction and a NaAc/EtOHprecipitation. As a methylation control genomic DNA of HeLaS3 was in vitro methylated using the $\mathrm{CpG}$ methylase SssI (New England Biolabs, Frankfurt am Main, Germany) according to the recommendations of the manufacturer.

Methylation-specific PCR. Promoter methylation of RASSF1A, p16, MGMT, DAPK1, RAR , MLH1, CHD1, GSTP1, RASSF5, MST1, MST2, LATS1 and LATS2 was analyzed by methylation-specific PCR (Table IV). Therefore, bisulfite-treated DNA samples were amplified with methylation- and unmethylation specific primers by a standard PCR protocol $(20,21)$. All PCR products were analyzed on $2 \%$ TBE agarose gels.

Combined bisulfite restriction analysis. Methylation of RASSF 2 and RASSF4 was analyzed using the combined bisulfite restriction analysis (22). Bisulfite treated DNA was amplified with primers specific for RASSF2 or RASSF4 (Table IV). For RASSF2 a semi-nested PCR using an internal primer was performed. PCR products $(20-50 \mathrm{ng})$ were restricted with 10 units of BstUI (New England Biolabs, Beverly, MA) according to the manufacturer's protocol and analyzed on $2 \%$ TBE agarose gels.

Statstics. All statistical correlations were performed by SPSS 15.0 (Chicago, IL, USA).

\section{Results}

Frequent methylation of tumor-related genes in head and neck cancer. Methylation status of $15 \mathrm{CpG}$ island promoters of tumor related genes (RASSF1A, p16, MGMT, DAPK, RAR 3 , MLH1, CDH1, GSTP1, RASSF2, RASSF4, RASSF5, MST1, MST2, LATS1 and LATS2) was analyzed in 54 head and neck squamous cell carcinoma (HNSCC) and 23 matching normal tissues. Representative data are shown in Fig. 1 and results are summarized in Table II. Combined methylation of TRG $(n=15)$ was $42 \%$ in primary HNSCC (Table II) and this methylation was significantly higher compared to normal matching tissues (23\%; $\mathrm{p}=0.04$, Fisher's exact test). Hypermethylation of p16 (60\%), MGMT (53\%), DAPK (67\%), RARß (75\%), MLH1 (69\%), CDH1 (43\%), RASSF5 and MST1 $(96 \%)$ was frequently observed in HNSCC. Methylation of RASSF1A (18\%), GSTP1 (4\%), RASSF4 (13\%), MST2 (4\%), LATS1 (24\%) and LATS2 (8\%) was less frequently detected. No significant correlation between methylation of TRG was found. Only methylation of MST2 occurred more frequent in normal tissues (55\%) compared to HNSCC (4\%). Methylation of RASSF1A and RASSF4 was not detected in normal matching samples (Table II). To confirm the aberrant methylation of TRG in established head and neck cancer, we analyzed the methylation status in three head and neck cancer cell lines (Table II). The methylation index of 15 TRG in cancer cell lines $(44 \%)$ was similar compared to primary HNSCC (42\%; Table II). Our results show that methylation of TRG is frequent in head and neck cancer. 


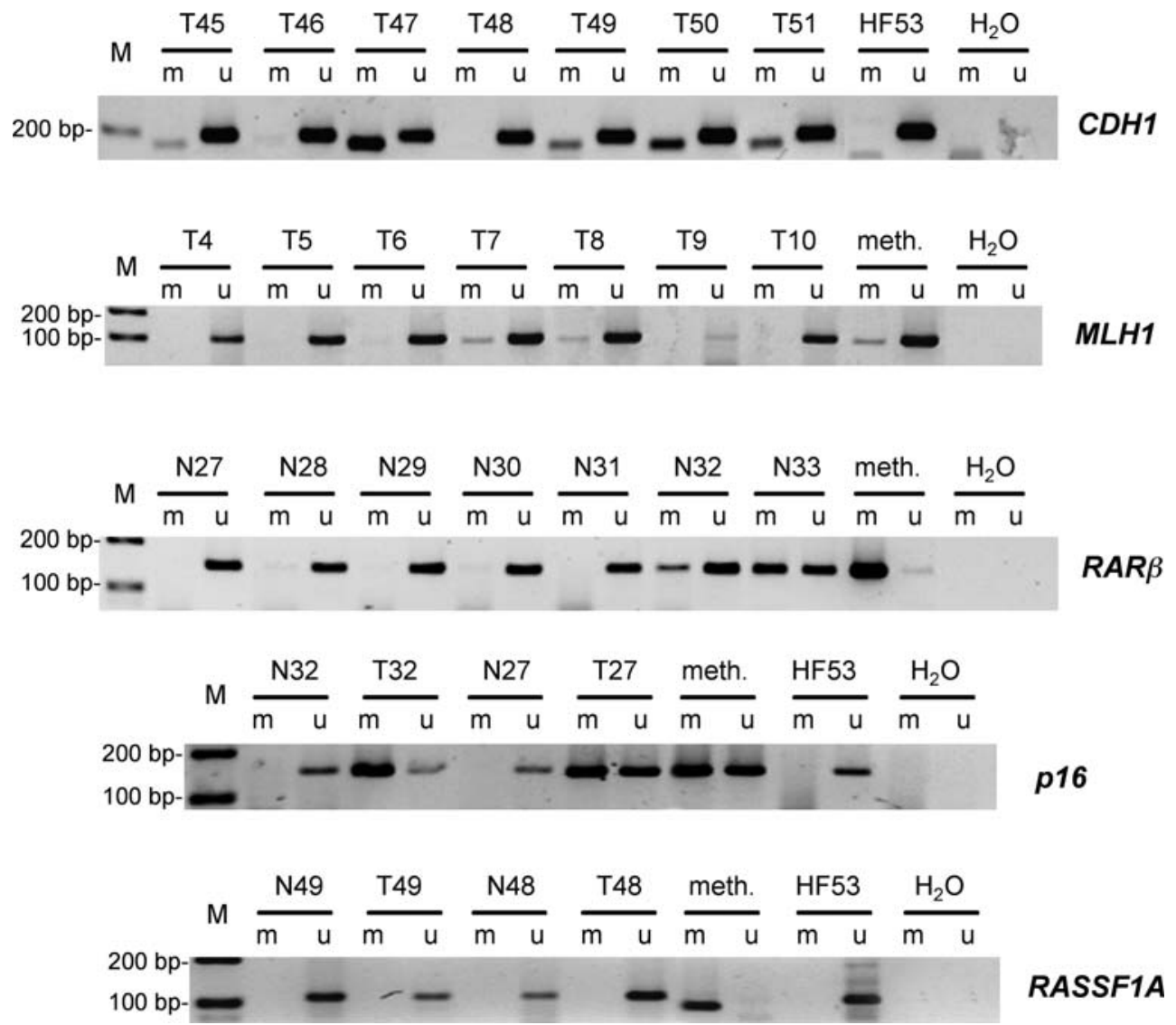

Figure 1. Methylation analysis in primary head and neck tissue samples. Representative results of the methylation specific PCR (MSP) of $C D H 1, M L H 1$, $R A R \beta, p 16$ and RASSF1A. Bisulfite treated DNA from HNSCC $(\mathrm{T})$ and matching normal tissues $(\mathrm{N})$ were amplified with methylation specific primers (m) and unmethylation specific primers (u) together with controls (human fibroblast DNA, HF53; in vitro methylated DNA, meth. and water, $\mathrm{H}_{2} \mathrm{O}$ ). PCR products were separated on $2 \%$ TBE agorose gels with a 100 bp marker (M).

Table II. Summary of methylation analyses.

\begin{tabular}{|c|c|c|c|c|c|}
\hline & $\begin{array}{c}\text { Primary HNSCC } \\
n=54(\%)\end{array}$ & $\begin{array}{c}\text { Normal tissues } \\
n=23(\%)\end{array}$ & $\begin{array}{c}\text { Cancer cell lines } \\
n=3(\%)\end{array}$ & $\begin{array}{c}\text { Recurrence } \\
\mathrm{n}=30(\%)\end{array}$ & $\begin{array}{c}\text { No recurrence } \\
n=20(\%)\end{array}$ \\
\hline RASSF $1 A$ & 18 & 0 & 66 & 17 & 24 \\
\hline p16 & 60 & 24 & 0 & 64 & 60 \\
\hline$M G M T$ & 53 & 29 & 100 & 48 & 59 \\
\hline$D A P K 1$ & 67 & 33 & 66 & 59 & 72 \\
\hline$R A R \beta$ & 75 & 47 & 66 & 81 & 81 \\
\hline$M L H 1$ & 69 & 45 & 66 & 68 & 71 \\
\hline$C D H 1$ & 43 & 8 & 0 & 45 & 40 \\
\hline GSTP1 & 4 & 5 & 0 & 7 & 0 \\
\hline RASSF2 & 41 & 11 & 33 & 41 & 45 \\
\hline RASSF4 & 13 & 0 & 0 & $23^{\mathrm{a}}$ & $0^{\mathrm{a}}$ \\
\hline RASSF5 & 58 & 17 & 100 & 57 & 55 \\
\hline MST1 & 96 & 42 & 100 & 96 & 94 \\
\hline MST2 & 4 & 55 & 0 & 7 & 0 \\
\hline LATS1 & 24 & 23 & 0 & 17 & 25 \\
\hline LATS2 & 8 & 9 & 66 & 3 & 15 \\
\hline \multicolumn{6}{|c|}{ MI $(n=15)(\%)$} \\
\hline$\pm \mathrm{SD}$ & $42 \pm 28$ & $23 \pm 17$ & $44 \pm 40$ & $42 \pm 28$ & $42 \pm 30$ \\
\hline
\end{tabular}

Significant changes are indicated in bold: ${ }^{\mathrm{a}} \mathrm{p}=0.033$ (Fisher's exact test); MI, methylation index; SD, standard deviation. 
Table III. Correlation of methylation and clinicopathological characteristics.

\begin{tabular}{|c|c|c|c|c|c|c|c|c|c|c|c|c|c|c|c|c|}
\hline & \multirow[b]{2}{*}{ Age } & \multicolumn{4}{|c|}{ Staging } & \multicolumn{3}{|c|}{ Differentiation } & \multicolumn{4}{|c|}{ T-stage } & \multicolumn{4}{|c|}{$\mathrm{N}$-stage } \\
\hline & & I & II & III & IV & G1 & $\mathrm{G} 2$ & G3 & $\mathrm{T} 1$ & $\mathrm{~T} 2$ & $\mathrm{~T} 3$ & $\mathrm{~T} 4$ & No & N1 & $\mathrm{N} 2$ & N3 \\
\hline \multicolumn{17}{|c|}{ RASSF1A } \\
\hline $\mathrm{m}(\%)$ & & 33 & - & 10 & 21 & 0 & 21 & 8 & 25 & 25 & 14 & 8 & 10 & 14 & 16 & 33 \\
\hline $\mathrm{m}$ & $51 \pm 8$ & 1 & 0 & 1 & 6 & 0 & 6 & 1 & 2 & 2 & 3 & 1 & 1 & 1 & 4 & 2 \\
\hline $\mathrm{u}$ & $57 \pm 10$ & 2 & 0 & 9 & 29 & 4 & 23 & 11 & 6 & 6 & 18 & 11 & 9 & 6 & 21 & 4 \\
\hline \multicolumn{17}{|l|}{ pl6 } \\
\hline $\mathrm{m}(\%)$ & & 66 & - & 50 & 57 & 50 & $43^{a}$ & $83^{a}$ & 63 & 75 & 48 & 54 & 50 & 43 & 64 & 57 \\
\hline $\mathrm{m}$ & $58 \pm 11$ & 2 & 0 & 5 & 20 & 2 & 13 & 10 & 5 & 6 & 10 & 7 & 5 & 3 & 16 & 4 \\
\hline $\mathrm{u}$ & $54 \pm 7$ & 1 & 0 & 5 & 15 & 2 & 17 & 2 & 3 & 2 & 11 & 6 & 5 & 4 & 9 & 3 \\
\hline
\end{tabular}

\section{MGMT}

$\mathrm{m}(\%)$

$\mathrm{m}$

u

DAPK1

$\mathrm{m}(\%)$

$\mathrm{m}$

u

$R A R \beta$

$\mathrm{m}(\%)$

$\mathrm{m}$

u

MLH1

$\mathrm{m}(\%)$

$\mathrm{m}$

u

$\mathrm{CDH1}$

$\mathrm{m}(\%)$

$\mathrm{m}$

u

GSTP1

$\mathrm{m}(\%)$

$\mathrm{m}$

u

RASSF 2

$\mathrm{m}(\%)$

$\mathrm{m}$

u

RASSF 4

$\mathrm{m}(\%)$

$\mathrm{m}$

u

RASSF5

m (\%)

$\mathrm{m}$

$\mathrm{u}$ $\begin{array}{rrrrr} & 33 & - & 60 & 53 \\ 59 \pm 10 & 1 & 0 & 6 & 17\end{array}$

$\begin{array}{lllll}55 \pm 9 & 2 & 0 & 4 & 15\end{array}$ $\begin{array}{lllll}25 & 56 & 58 & 33 & 5\end{array}$

$\begin{array}{llll}1 & 15 & 7 & 3 \\ 3 & 12 & 5 & 6\end{array}$

$33 \quad-\quad 40 \quad 74 \quad 100 \quad 62$

$\begin{array}{lllllll}58 \pm 8 & 1 & 0 & 4 & 25 & 2 & 18\end{array}$

$\begin{array}{lllllll}58 \pm 12 & 2 & 0 & 6 & 9 & 0 & 11\end{array}$

$\begin{array}{rrrrrrrrr}69 & 86 & 63 & 67 & 58 & 38 & 57 & 80 & 57 \\ 9 & 6 & 5 & 14 & 7 & 3 & 4 & 20 & 4 \\ 4 & 1 & 3 & 7 & 5 & 5 & 3 & 5 & 3\end{array}$

$\begin{array}{lllllllllllllll}100 & - & 60 & 75 & 50 & 78 & 67 & 89 & 83 & 74 & 75 & 71 & 83 & 78 & 67\end{array}$

$\begin{array}{lllllllllllllll}58 \pm 9 & 3 & 0 & 3 & 24 & 4 & 18 & 8 & 8 & 5 & 14 & 6 & 5 & 5 & 18\end{array}$

$\begin{array}{lllllllllllllll}55 \pm 8 & 0 & 0 & 2 & 8 & 4 & 5 & 4 & 1 & 1 & 5 & 2 & 2 & 1 & 5\end{array}$ 
Table III.Continued.

\begin{tabular}{|c|c|c|c|c|c|c|c|c|c|c|c|c|c|c|c|c|}
\hline & \multirow[b]{2}{*}{ Age } & \multicolumn{4}{|c|}{ Staging } & \multicolumn{3}{|c|}{ Differentiation } & \multicolumn{4}{|c|}{ T-stage } & \multicolumn{4}{|c|}{ N-stage } \\
\hline & & I & II & III & IV & G1 & G2 & G3 & $\mathrm{T} 1$ & $\mathrm{~T} 2$ & $\mathrm{~T} 3$ & $\mathrm{~T} 4$ & No & N1 & N2 & N3 \\
\hline \multicolumn{17}{|l|}{ MST1 } \\
\hline $\mathrm{m}(\%)$ & & 67 & - & 100 & 94 & 67 & 96 & 100 & 86 & 86 & 100 & 100 & 88 & 100 & 100 & 100 \\
\hline $\mathrm{m}$ & $58 \pm 10$ & 2 & 0 & 8 & 31 & 2 & 26 & 13 & 6 & 6 & 20 & 12 & 7 & 6 & 24 & 6 \\
\hline $\mathrm{u}$ & $71 \pm 9$ & 1 & 0 & 0 & 2 & 1 & 1 & 0 & 1 & 1 & 0 & 0 & 1 & 0 & 0 & 0 \\
\hline \multicolumn{17}{|l|}{$M S T 2$} \\
\hline $\mathrm{m}(\%)$ & & 0 & - & 10 & 3 & 0 & 4 & 7 & 0 & 13 & 5 & 0 & 10 & 0 & 4 & 0 \\
\hline $\mathrm{m}$ & $73 \pm 4$ & 0 & 0 & 1 & 1 & 0 & 1 & 1 & 0 & 1 & 1 & 0 & 1 & 0 & 1 & 0 \\
\hline $\mathrm{u}$ & $57 \pm 9$ & 3 & 0 & 9 & 32 & 4 & 26 & 13 & 9 & 7 & 20 & 10 & 9 & 6 & 23 & 7 \\
\hline \multicolumn{17}{|l|}{ LATS1 } \\
\hline $\mathrm{m}(\%)$ & & 0 & - & 9 & 26 & 0 & 20 & 23 & 0 & 13 & 39 & 9 & 9 & 14 & 33 & 14 \\
\hline $\mathrm{m}$ & $62 \pm 9$ & 0 & 0 & 1 & 9 & 0 & 6 & 3 & 0 & 1 & 9 & 1 & 1 & 1 & 8 & 1 \\
\hline $\mathrm{u}$ & $56 \pm 10$ & 3 & 0 & 10 & 25 & 4 & 24 & 10 & 8 & 7 & 14 & 10 & 10 & 6 & 16 & 6 \\
\hline \multicolumn{17}{|l|}{ LATS2 } \\
\hline $\mathrm{m}(\%)$ & & 0 & - & 9 & 6 & 0 & 6 & 14 & 0 & 0 & 9 & 15 & 9 & 0 & 8 & 14 \\
\hline $\mathrm{m}$ & $55.5 \pm 2$ & 0 & 0 & 1 & 2 & 0 & 2 & 2 & 0 & 0 & 2 & 2 & 1 & 0 & 2 & 1 \\
\hline $\mathrm{u}$ & $57 \pm 10$ & 3 & 0 & 10 & 34 & 4 & 30 & 12 & 9 & 8 & 20 & 11 & 10 & 7 & 24 & 6 \\
\hline $\begin{array}{l}\text { MI }(n=15)(\%) \\
\pm \text { SD }\end{array}$ & & $31 \pm 31$ & - & $36 \pm 28$ & $44 \pm 28$ & $29 \pm 30$ & $41 \pm 28$ & $45 \pm 31$ & $37 \pm 31$ & $41 \pm 30$ & $41 \pm 28$ & $44 \pm 32$ & $37 \pm 30$ & $36 \pm 30$ & $45 \pm 30$ & $45 \pm 28$ \\
\hline
\end{tabular}

Significant changes (Fisher's exact test) are indicated in bold: ${ }^{\mathrm{a}} \mathrm{p}=0.037$ (G2 vs G3) and ${ }^{\mathrm{b}} \mathrm{p}<0.05$ (T4 vs. T3, T2 and T1); MI, methylation index; SD, standard deviation.

Increased promoter methylation of tumor-related genes occurs in advanced HNSCC. Subsequently, we determined if promoter hypermethylation correlated with different clinicopathological parameters including recrudescence, age, stage, differentiation and TNM staging and lymph node status (Tables II and III). No significant methylation differences between recurrent and non-recurrent tumors were observed (42 vs. 43\%, respectively; Table II). However, RASSF4 methylation was preferentially detected in recurrences $(\mathrm{p}=0.033)$. Methylation of TRG was not associated with aging (Table III). In stage IV HNSCC combined methylation (44\%) was higher compared to stage III (36\%) and methylation of RASSF $1 A$, DAPK1, MLH1, CDH1, RASSF 4 and LATS1 increased considerably (Table III). Methylation index of TRG in poorly differentiated HNSCC (45\%) was noticeably higher compared to well differentiated tumors $(29 \%)$. In poorly differentiated HNSCC methylation of p16, MGMT, RASSF5, MST1, LATS1 and LATS2 was more pronounced compared to moderately differentiated HNSCC (Table III) and this trend was significant for $p 16$ (43 vs. 83\%, respectively; $\mathrm{p}=0.037$ ). Combined methylation of TRG in stage T4 (44\%) was higher compared to stage T1 (37\%). Methylation of RASSF2, RASSF5 and LATS2 occurred more frequent in stage 4 than in lower stages and this trend was significant for RASSF 5 ( $\mathrm{p}<0.05)$. In HNSCC with increased involvement of cancerous lymph node (N2 and N3), a higher methylation index (45\%) compared to N0 (37\%) was found (Table III). Particularly hypermethylation of RASSF $1 A$ and RASSF4 was observed in N3 compared to N0 (Table III). In summary, these data indicate a higher methylation frequency of TRG in more advanced HNSCC.

\section{Discussion}

HNSCC is one of the most frequent cancers and therefore new biomarkers for early diagnosis and to predict prognosis are important. Promoter hypermethylation of tumor-related genes (TRG) is a promising new tool for these issues $(9,23)$. In our study, we evaluated the promoter hypermethylation of 15 TRG in primary HNSCC and matching normal tissues. Methylation of several TRG was preferentially found in HNSCC indicating a cancer relevant event of TRG silencing. Tumor specific methylation of several members of RASSFS (RASSF1A, RASSF2, RASSF4 and RASSF5) and downstream effectors (MST1, LATS1 and LATS2) was found (Table II). Methylation of certain TRG was neither co-segregating nor mutually exclusive.

In previous work, we have identified the RASSF $1 A$ tumor suppressor gene, which is frequently hypermethylated in primary tumors, including lung cancer (40-80\%) (24-26). In HNSCC, RASSF1A methylation is less frequent (18\%) and this was previously observed $(12,27,28)$. Interestingly, RASSF 1A methylation was only found in tumors and not in normal mucosa from cancer patients and increased in more 
Table IV. Primers and conditions for methylation-specific PCR (MSP) and COBRA.

\begin{tabular}{|c|c|c|c|}
\hline & Forward primer (5'-3') & Reverse primer (5'-3') & Length (bp) \\
\hline \multirow[t]{2}{*}{ RASSF1A } & M: GTGTTAACGCGTTGCGTATC & M: AACCCCGCGAACTAAAAACGA & 94 \\
\hline & U: TTTGGTTGGAGTGTGTTAATGTG & U:CAAACCCCACAAACTAAAAACAA & 108 \\
\hline \multirow[t]{2}{*}{ pl6 } & M: TTATTAGAGGGTGGGGCGGATCGC & M: GACCCCGAACCGCGACCGTAA & 150 \\
\hline & U: TTATTAGAGGGTGGGGTGGATTGT & U: CAACCCCAAACCACAACCATAA & 151 \\
\hline \multirow[t]{2}{*}{$M G M T$} & M: TTTCGACGTTCGTAGGTTTTCGC & M: GCACTCTTCCGAAAACGAAACG & 81 \\
\hline & U: TTTGTGTTTTGATGTTTGTAGGTTTTTGT & U:AАCTCCACACTCTTCCAAAAАCAAАACA & 93 \\
\hline \multirow[t]{2}{*}{$D A P K$} & M: GGATAGTCGGATCGAGTTAACGTC & M: CCCTCCCAAACGCCGA & 98 \\
\hline & U: GGAGGATAGTTGGATTGAGTTAATGTT & U: CAAATCCCTCCCAAACACCAA & 106 \\
\hline \multirow[t]{2}{*}{$R A R \beta$} & M: TCGAGAACGCGAGCGATTCG & M: GACCAATCCAACCGAAACGA & 146 \\
\hline & U: TTGAGAATGTGAGTGATTTGA & U: AACCAATCCAACCAAAACAA & 146 \\
\hline \multirow[t]{2}{*}{$M L H 1$} & M: AACGAATTAATAGGAAGAGCGGATAGCG & M: CGTCCCTCCCTAAAACCGACTACTACCC & 91 \\
\hline & U: TAAAAATGAATTAATAGGAAGAGTGGATAGTG & U: ААТСТСТTСАТСССТСССТААААСА & 102 \\
\hline \multirow[t]{2}{*}{$\mathrm{CDHI}$} & M: GGTGAATTTTTAGTTAATTAGCGGTAC & M: CATAACTAACCGAAAACGCCG & 204 \\
\hline & U: GGTAGGTGAATTTTTAGTTAATTAGTGGTA & U: ACCCATAACTAACCAAAAACACCA & 211 \\
\hline \multirow[t]{2}{*}{ GSTP1 } & M: TTCGGGGTGTAGCGGTCGTC & M: GCCCCAATACTAAATCACGACG & 91 \\
\hline & U: GATGTTTGGGGTGTAGTGGTTGTT & U: CCACCCCAATACTAAATCACAACA & 97 \\
\hline \multirow[t]{2}{*}{$R A S S F 2$} & F: GGTGTAGGGTTGGGGAGGGTTTGAT & R1: AACAAAACCCTCAATCTCCCTATAAAACCA & 384 \\
\hline & & R2: CCCAACCACCTCAAACACCAАCTCC & 220 \\
\hline RASSF4 & F: GTAGCGGTTTTTGTTGGAAGTTTAGGAGTT & R: AGTTGAATAATGGTTTGGGGATATTTGGT & 174 \\
\hline \multirow[t]{2}{*}{ RASSF5 } & M: CGTCGTTTGGTACGGATTTTATTTTTTTCGGTTC & M: GACAACTTTAACAACGACGACTTTAACGACTACG & 202 \\
\hline & U: ATTTATATTTGTGTAGATGTTGTTTGGTAT & U: АCTTTAACAACAACAACTTTAACAACTACA & 215 \\
\hline \multirow[t]{2}{*}{ MST1 } & M: GCGGGGCGGGTTTAGGAGGTTC & M: CCAATAACCCCTCACCGACGCG & 120 \\
\hline & U: TTTGTGGGGTGGGTTTAGGAGGTTTGT & U: AACCAATAACCCCTCACCAACACAACAA & 125 \\
\hline \multirow[t]{2}{*}{ MST2 } & M: CGGGAGGGAGATTCGTCGCG & M: AAACCGAAACACCGACCGACCG & 99 \\
\hline & U: TTTTAAGTGGGAGGGAGATTTGTTGTGG & U: AAAAACCAAAACACCAACCAACCAAACC & 108 \\
\hline \multirow[t]{2}{*}{ LATS1 } & M: GAACGATTAGAGTTGCGGGCGAC & M: TGAATGATTAGAGTTGTGGGTGATGT & 126 \\
\hline & U: AACATTTCCCGACGTCGCTTACG & U: AAACATTTCCCAACATCACTTACACA & 128 \\
\hline \multirow[t]{2}{*}{ LATS2 } & M: TTCGTTCGGATTGGTATGCGGTC & M: CCATCTTCCCGAAACGCTCACG & 137 \\
\hline & U: GGTGTTTTGTTTGGATTGGTATGTGGTT & U: CATCTTCCCAAAACACTCACACCACA & 141 \\
\hline
\end{tabular}

M, methylation specific primer; $U$, unmethylation specific primer; $F$, forward primer; $R$, reverse primer.

advanced tumor stages and when more affected lymph node were involved (Table III). Methylation of RASSF4 was rather infrequent and this was also reported for nasopharyngeal cancer (29). However, a trend for higher RASSF4 methylation was detected in recurrent HNSCC, stage IV and N3 HNSCCs. RASSF $1 A$ and RASSF4 are tumor suppressors and participate in the proapopotic Hippo-pathway (Hpo; drosophila MST homologue) through a Sav-RASSF-Hpo domain, which is located at their C-terminus (30). This Sav-RASSF-Hpo domain is also found in RASSF 2 and RASSF5 (NORE1). To our knowledge this is the first report of frequent methylation RASSF 2 and RASSF5 in HNSCC (41 and 58\%, respectively). Zhang et al have reported that RASSF2 methylation occurs in $51 \%$ of nasopharyngeal carcinoma and correlates with lymph node metastasis (31). Methylation of RASSF-dependent proapopotic kinase MST1 was frequently detected in HNSCC, however methylation of MST2 was not tumor specific (Table II). We and others have reported that MSTI is frequently methylated in soft tissue sarcoma and colorectal carcinoma $(21,32)$. Loss of cytoplasmic MST1 is associated with higher $\mathrm{T}$ and/or $\mathrm{N}$ stage, higher tumor grade and poor prognosis in colorectal cancer (32). Interestingly, methylation of MST1 occurred in all poorly differentiated HNSCC (Table III). Also methylation of LATS1 and LATS2 was more pronounced in dedifferentiated tumors. The large tumor suppressors LATS1 and LATS2 are MST and RASSF 
binding proteins that regulate apoptosis and mitotic exit $(33,34)$. Hypermethylation of LATS1 and LATS2 was previously reported only in sarcoma, breast cancer and astrocytoma $(21,35,36)$.

We detected frequent promoter methylation of the tumorrelated genes p16, MGMT, DAPK1, RARß, MLH1 and CDH1 in HNSCC (Table II). The revealed methylation frequency of these TRG is consistent with other studies $(11-13,16-18,28,37)$. Methylation of GSTPl in HNSCC is rarely observed $(13,17)$. Methylation index of TRG was more frequent in advanced tumor stages (IV, T4 and N3) and poorly differentiated HNSCC (G3; Table III). Methylation of MLH1, CDH1 and $D A P K 1$ was higher in stage IV. Sanchez-Cespedes et al have reported that methylation of DAPK1 correlates with an advance disease stage (17). Methylation of pl6 and MGMT was more frequent in poorly differentiated tumors (Table III). Zuo et al have reported that MGMT hypermethylation correlated with impaired prognosis and increased tumor recurrences (38). Hypermethylation of p16 was associated advanced oral squamous cell carcinoma and lymph node metastasis (13). Methylation of RASSF 1A, DAPK1 and $R A S S F 4$ increased with increased involvement of regional lymph nodes (Table III). It has been shown that DAPK1 methylation is significantly associated with lymph node involvement and metastases $(11,17)$.

Methylation of TRG (e.g.p16 and RARß) was also found in matching normal tissue (Table II). This result is consistent with previous reports that reveal frequent methylation of RARß (50\%), p16 (27\%), MGMT (41\%) and other TRG in normal mucosa of HNSCC patients (14-16). Aberrant promoter methylation of TRG (e.g. pl6 and DAPK1) is also found frequently in normal oral mucosa and bronchial brushes from smokers and former cigarette smokers, respectively $(39,40)$. These data indicate that promoter methylation of several TRG in pre-cancerous tissue is an early event and may occur as a result of exposure to different agents (e.g. alcohol, betel quid and tobacco) that were related to HNSCC $(5-7,41)$. To confirm this hypothesis it would be interesting to analyze methylation of TRG in normal mucosa of healthy persons, who were exposed to these substances or not. Increased TRG methylation in agent exposed mucosa may represent first pre-cancerous alterations and this could be used as a biomarker for HNSCC. However, methylation of TRG in body fluids of normal controls may affect the utility of hypermethylation detection strategy (23). Methylation of certain TRG (e.g. p16 and MGMT) could also be due to epigenetic field effects, which was reported for colorectal cancer and lung cancer (42-44). Interestingly, RASSF $1 A$ and RASSF4 methylation was not detected in matching normal mucosa.

In summary, our data show frequent hypermethylation of TRG in HNSCC and hypermethylation was considerably increased in more advanced HNSCC. To our knowledge this is the first report of methylation of RASSF2, RASSF4, RASSF5, MST1, LATS1 and LATS2 in HNSCC. RASSFs, MSTs and LATSs are prominent tumor suppressors and regulate microtubule stability, cell cycle and apoptosis $(30,33,34)$. Thus silencing of RASSF members and their downstream effectors may represent important events in head and neck carcinogenesis.

\section{Acknowledgements}

Reinhard Dammann received grant support from BMBF (FKZ 01ZZ0104), Deutsche Krebshilfe (107742) and DFG (DA552).

\section{References}

1. Parkin DM, Bray F, Ferlay J and Pisani P: Global cancer statistics, 2002. CA Cancer J Clin 55: 74-108, 2005.

2. Warnakulasuriya S: Global epidemiology of oral and oropharyngeal cancer. Oral Oncol 45: 309-316, 2009.

3. Jemal A, Siegel R, Ward E, et al: Cancer statistics, 2008. CA Cancer J Clin 58: 71-96, 2008.

4. Vokes EE, Weichselbaum RR, Lippman SM and Hong WK: Head and neck cancer. N Engl J Med 328: 184-194, 1993.

5. Blot WJ, McLaughlin JK, Winn DM, et al: Smoking and drinking in relation to oral and pharyngeal cancer. Cancer Res 48: 3282-3287, 1988.

6. Rothman K and Keller A: The effect of joint exposure to alcohol and tobacco on risk of cancer of the mouth and pharynx. J Chronic Dis 25: 711-716, 1972.

7. Maier H, Dietz A, Gewelke U, Heller WD and Weidauer H: Tobacco and alcohol and the risk of head and neck cancer. Clin Investig 70: 320-327, 1992.

8. Jones PA and Baylin SB: The fundamental role of epigenetic events in cancer. Nat Rev Genet 3: 415-428, 2002.

9. Brena RM, Huang TH and Plass C: Quantitative assessment of DNA methylation: potential applications for disease diagnosis, classification, and prognosis in clinical settings. J Mol Med 84: 365-377, 2006.

10. Ha PK and Califano JA: Promoter methylation and inactivation of tumour-suppressor genes in oral squamous-cell carcinoma. Lancet Oncol 7: 77-82, 2006.

11. Calmon MF, Colombo J, Carvalho F, et al: Methylation profile of genes CDKN2A (p14 and p16), DAPK1, CDH1, and ADAM23 in head and neck cancer. Cancer Genet Cytogenet 173: 31-37, 2007.

12. Hasegawa M, Nelson HH, Peters E, Ringstrom E, Posner M and Kelsey KT: Patterns of gene promoter methylation in squamous cell cancer of the head and neck. Oncogene 21: 4231-4236, 2002.

13. Ishida E, Nakamura M, Ikuta M, et al: Promotor hypermethylation of p14ARF is a key alteration for progression of oral squamous cell carcinoma. Oral Oncol 41: 614-622, 2005.

14. Kato K, Hara A, Kuno T, et al: Aberrant promoter hypermethylation of p16 and MGMT genes in oral squamous cell carcinomas and the surrounding normal mucosa. J Cancer Res Clin Oncol 132: 735-743, 2006.

15. Kulkarni V and Saranath D: Concurrent hypermethylation of multiple regulatory genes in chewing tobacco associated oral squamous cell carcinomas and adjacent normal tissues. Oral Oncol 40: 145-153, 2004.

16. Maruya S, Issa JP, Weber RS, et al: Differential methylation status of tumor-associated genes in head and neck squamous carcinoma: incidence and potential implications. Clin Cancer Res 10: 3825-3830, 2004.

17. Sanchez-Cespedes M, Esteller M, Wu L, et al: Gene promoter hypermethylation in tumors and serum of head and neck cancer patients. Cancer Res 60: 892-895, 2000.

18. Viswanathan M, Tsuchida N and Shanmugam G: Promoter hypermethylation profile of tumor-associated genes $\mathrm{p} 16, \mathrm{p} 15$, hMLH1, MGMT and E-cadherin in oral squamous cell carcinoma. Int J Cancer 105: 41-46, 2003.

19. Wittekind C, Meyer H-J and Bootz F: UICC: TNM Klassifikation maligner Tumoren. 6th edition. Berlin, Heidelberg, New York, Springer, 2002.

20. Schagdarsurengin U, Gimm O, Dralle H, Hoang-Vu C and Dammann R: $\mathrm{CpG}$ island methylation of tumor-related promoters occurs preferentially in undifferentiated carcinoma. Thyroid 16: 633-642, 2006.

21. Seidel C, Schagdarsurengin U, Blumke K, et al: Frequent hypermethylation of MST1 and MST2 in soft tissue sarcoma. Mol Carcinog 46: 865-871, 2007.

22. Eads $C A$ and Laird PW: Combined bisulfite restriction analysis (COBRA). Methods Mol Biol 200: 71-85, 2002.

23. Carvalho AL, Jeronimo C, Kim MM, et al: Evaluation of promoter hypermethylation detection in body fluids as a screening/ diagnosis tool for head and neck squamous cell carcinoma. Clin Cancer Res 14: 97-107, 2008. 
24. Dammann R, Li C, Yoon JH, Chin PL, Bates S and Pfeifer GP Epigenetic inactivation of a RAS association domain family protein from the lung tumour suppressor locus $3 \mathrm{p} 21.3$. Nat Genet 25: 315-319, 2000.

25. Dammann R, Schagdarsurengin U, Seidel C, et al: The tumor suppressor RASSF1A in human carcinogenesis: an update. Histol Histopathol 20: 645-663, 2005.

26. Dammann R, Takahashi T and Pfeifer GP: The CpG island of the novel tumor suppressor gene RASSF1A is intensely methylated in primary small cell lung carcinomas. Oncogene 20: 3563-3567, 2001.

27. Hogg RP, Honorio S, Martinez A, et al: Frequent 3p allele loss and epigenetic inactivation of the RASSF1A tumour suppressor gene from region 3p21.3 in head and neck squamous cell carcinoma. Eur J Cancer 38: 1585-1592, 2002.

28. Hoque MO, Begum S, Topaloglu O, et al: Quantitative detection of promoter hypermethylation of multiple genes in the tumor, urine, and serum DNA of patients with renal cancer. Cancer Res 64: 5511-5517, 2004.

29. Chow LS, Lo KW, Kwong J, Wong AY and Huang DP: Aberrant methylation of RASSF4/AD037 in nasopharyngeal carcinoma. Oncol Rep 12: 781-787, 2004.

30. Richter AM, Pfeifer GP and Dammann RH: The RASSF proteins in cancer; from epigenetic silencing to functional characterization. Biochim Biophys Acta (In press).

31. Zhang Z, Sun D, Van do N, Tang A, Hu L and Huang G: Inactivation of RASSF2A by promoter methylation correlates with lymph node metastasis in nasopharyngeal carcinoma. Int J Cancer 120: 32-38, 2007.

32. Minoo P, Zlobec I, Baker K, et al: Prognostic significance of mammalian sterile20-like kinase 1 in colorectal cancer. Mod Pathol 20: 331-338, 2007.

33. Guo C, Tommasi S, Liu L, Yee JK, Dammann R and Pfeifer GP: RASSF1A is part of a complex similar to the Drosophila Hippo/Salvador/Lats tumor-suppressor network. Curr Biol 17: 700-705, 2007.

34. Matallanas D, Romano D, Yee K, et al: RASSF1A elicits apoptosis through an MST2 pathway directing proapoptotic transcription by the p73 tumor suppressor protein. Mol Cell 27: 962-975, 2007.
35. Jiang Z, Li X, Hu J, et al: Promoter hypermethylation-mediated down-regulation of LATS1 and LATS2 in human astrocytoma. Neurosci Res 56: 450-458, 2006.

36. Takahashi Y, Miyoshi Y, Takahata C, et al: Down-regulation of LATS1 and LATS2 mRNA expression by promoter hypermethylation and its association with biologically aggressive phenotype in human breast cancers. Clin Cancer Res 11: 1380-1385, 2005.

37. Zhang S, Guo C, Kong W and Liu Z: Promoter hypermethylation of DNA repair gene MGMT in laryngeal squamous cell carcinoma. J Huazhong Univ Sci Technolog Med Sci 26: 101-104, 2006.

38. Zuo C, Ai L, Ratliff P, et al: O6-methylguanine-DNA methyltransferase gene: epigenetic silencing and prognostic value in head and neck squamous cell carcinoma. Cancer Epidemiol Biomarkers Prev 13: 967-975, 2004.

39. Soria JC, Rodriguez M, Liu DD, Lee JJ, Hong WK and Mao L: Aberrant promoter methylation of multiple genes in bronchial brush samples from former cigarette smokers. Cancer Res 62: 351-355, 2002

40. Von Zeidler SV, Miracca EC, Nagai MA and Birman EG: Hypermethylation of the p16 gene in normal oral mucosa of smokers. Int J Mol Med 14: 807-811, 2004.

41. Takeshima M, Saitoh M, Kusano K, et al: High frequency of hypermethylation of $\mathrm{p} 14, \mathrm{p} 15$ and $\mathrm{p} 16$ in oral pre-cancerous lesions associated with betel-quid chewing in Sri Lanka. J Oral Pathol Med 37: 475-479, 2008.

42. Dammann R, Strunnikova M, Schagdarsurengin U, et al: $\mathrm{CpG}$ island methylation and expression of tumour-associated genes in lung carcinoma. Eur J Cancer 41: 1223-1236, 2005.

43. Issa JP, Ahuja N, Toyota M, Bronner MP and Brentnall TA: Accelerated age-related $\mathrm{CpG}$ island methylation in ulcerative colitis. Cancer Res 61: 3573-3577, 2001.

44. Shen L, Kondo Y, Rosner GL, et al: MGMT promoter methylation and field defect in sporadic colorectal cancer. J Natl Cancer Inst 97: 1330-1338, 2005 . 